\title{
Dioxins in remediation workers
}

\author{
C. Winder ${ }^{1} \&$ G. Smith ${ }^{2}$ \\ ${ }^{1}$ School of Risk and Safety Sciences, The University of New South Wales, \\ Sydney, Australia \\ ${ }^{2}$ AECOM, Gordon, NSW, Australia
}

\begin{abstract}
A survey was conducted on workers involved in the remediation of a large, chemically contaminated site in Sydney, Australia. Workers were monitored for chlorinated dioxin and furan congeners in blood lipids over a two year period. Baseline levels of blood dioxins in workers starting at the site were similar to background dioxin levels in Australians (below $10 \mathrm{pg} / \mathrm{g}$ blood lipids). An action level of double the background levels (20 pg/g blood lipids) was used as an occupational health limit. As time progressed, blood lipid levels in workers increased, with the most likely source being exposure while working at the site. While levels of most congeners remain relatively even, most striking was the proportion of tetrachloro-congeners in exposed workers, which increased steadily. Worker exposure was above the action level in a small number of workers; these workers were transferred to other projects where the potential for dioxin exposure was absent. The role of congener profiling in occupational biological monitoring may provide additional information on workplace exposure to dioxins and related compounds.
\end{abstract}

Keywords: polychlorinated dioxins, worker exposure, environmental remediation, biological monitoring.

\section{Introduction}

The polychlorinated dioxins (CDDs) and furans (CDFs), are a group of materials that is often associated with wastes and waste disposal, and one particular member of this group, 2,3,7,8-tetrachlorodibenzo-p-dioxin (TCDD) is often incorrectly called "the most toxic chemical ever found" [1]. While 2,3,7,8tetrachlorodibenzo-p-dioxin is the most toxic of the CDDs, the other CDD/CDFs also have varying toxicities, and the range of toxicities can differ by a factor of 
10,000. Also, while there are a few CDDs and CDFs whose potency is well known, the toxicity of most are poorly characterised [2]. In addition, $\mathrm{CDD} / \mathrm{CDFs}$ are most often found in mixtures of congeners rather than as single compounds in the environment. A shorthand method of assessing the toxicity of different mixtures of $\mathrm{CDD} / \mathrm{CDF}$ congeners has been developed by comparing the toxicity of different individual congeners and homologues of $\mathrm{CDD} / \mathrm{CDF}$ to the toxicity of the most toxic congener, 2,3,7,8-TCDD. Using this system, a toxicity equivalence (TEQ) scale can be developed. By setting the toxicity of 2,3,7,8tetrachlorodibenzo-p-dioxin arbitrarily at one, other CDDs and CDFs can be measured as the fraction of 2,3,7,8-tetrachlorodibenzo-p-dioxin's activity to the criteria [3]. The concentrations of CDDs and CDFs emitted from incinerator stacks can then be reported in terms of toxic equivalents (TEQ), or in terms of the known toxicity of 2,3,7,8-tetrachlorodibenzo-p-dioxin.

Most emission and environmental data post-1988 are generally reported solely as TEQs, as reporting total amounts of $\mathrm{CDD} / \mathrm{CDFs}$ provides little data on toxicity. Reviews of the use of toxicity equivalency factors were published by the WHO in 1998 [4], and US EPA in 2000 [5]. These reviews conclude that the TEQ approach remains the most appropriate approach for estimating the toxicity of dioxin and furan mixtures.

Exposure to dioxins is predominantly in diet with $90-95 \%$ from this source. Well established foods with increased dioxin levels include dairy products, fish and meat. The risks to some groups of the population (for example breastfed babies) may be greater than can be predicted, because of increased relative levels of CDDs and CDFs in the diet of such individuals.

Dioxins have been reported to produce a number of health problems in humans. Workers exposed to high levels of dioxins develop a skin condition called chloracne, and workers exposed to very high levels of dioxins have a higher risk of developing cancers later in life. The available evidence suggests that 2,3,7,8-tetrachlorodibenzo- $p$-dioxin is a tumour promoter, not a tumour initiator [6-9]. Nevertheless, 2,3,7,8-tetrachlorodibenzo-p-dioxin is classified as a carcinogen [10-12].

Other studies at higher exposures show that dioxin exposure can lead to reproductive and developmental problems, increased heart disease and increased diabetes. Dioxin's ability to cause birth defects (teratogenicity) has not been established in humans but studies in mice have shown that dioxin and similar chemicals can produce congenital defects.

In 2002, the National Dioxins Program of the Australian National Medical Research Council (NHMRC) report that studies in dioxin dosed animals show effects on the immune system, nervous system, reproductive system, and during development. Workers exposed to high levels of dioxins develop a skin condition called chloracne, and workers exposed to very high levels of dioxins have a higher risk of developing cancers later in life. The NHMRC conclude: "However, the exact impact of dioxin on people's health is not yet known, and there is currently no clear indication that dioxins are causing increased disease in the general population." 
More critical is the dose response relationship for dioxins, and the possibility of establishing no effect levels and possibly recommendations for human exposure. Based on work of the National Dioxins Program of the Australian National Medical Research Council (NHMRC), and review of international evaluations of the WHO, US EPA, European Community and the Joint FAO/WHO Expert Committee on Food Additives, a tolerable monthly input (TMI) of $70 \mathrm{pg} / \mathrm{kg}$ body weight a month was proposed for use in Australia. This is equivalent to $4900 \mathrm{pg} / \mathrm{person} / \mathrm{month}$ or $15 \mathrm{pg} / \mathrm{person} /$ day [13].

Based on a breath volume of $0.5 \mathrm{~L}$, a respiratory rate of twenty breathes a minute; a person inhales about $11 \mathrm{~m}^{3}$ of air a day. Based on the NHMRC TMI of $15 \mathrm{pg} / \mathrm{person} / \mathrm{day}$, and adopting extremely conservative assumptions that all of this $15 \mathrm{pg}$ is present in the air that a person inhales in a day, and assuming that all of the inhaled dioxin is absorbed, and assuming that there is no dioxin from any other source, a concentration of $15 \mathrm{pg} / 11 \mathrm{~m}^{3}$ calculates to an constant daily air concentration of about $1.4 \mathrm{pg} / \mathrm{m}^{3}$.

With regard to a value of a "normal" dioxin level, the Australian Government National Dioxins Program analysed dioxin levels in the over 9000 blood samples taken from Australian Population in 2004 [14]. Overall the levels in the Australian population are very low by international standards. The mean and median levels expressed as upper bound TEQ values for all pooled samples were 10.9 and $8.3 \mathrm{pg} / \mathrm{g}$ TEQ lipid, respectively. For males, and females the mean levels were 10.4 and $11.5 \mathrm{pg} / \mathrm{g}$ TEQ lipid, respectively. A direct relationship was also found of increasing dioxins in blood with increasing age, from about age 25 , increasing from 6.2 at age 25 to 27.9 at 80 .

Because of these phenomena, especially the age related changes, it is difficult to establish a baseline dioxin in blood level for use in Australia. However, from a practical perspective, the mean value reported in this study, of $10.9 \mathrm{pg} / \mathrm{g}$ blood lipids would seem suitable as a baseline level.

\section{The site}

The site was a former Chemical Manufacturing site in Sydney, first developed in the 1920's on a river embayment. A range of organic chemicals were manufactured for use in Australia, using local feedstocks (such as by-products from gas and coke processing at a nearby manufacturer to make wood preservatives such as creosote, and solvents, antiseptics, nitro-compounds and xanthates. By the 1940s additional chemicals manufactured for a large and rapidly growing agricultural sector included herbicides such as 2,4-D and 2,4,5-T and insecticides such as DDT. Further, factory and processing wastes from the manufacturing of these chemicals was used in land reclamation in nearby mangrove swamps along the embayment and produced substantial contamination of land. The company was purchased by a multinational company in 1955, and continued producing chemicals (and reclaiming land with its waste products) until 1985. The land reclamation activities were never fully documented and the scale of contamination is unknown but considered substantial. One problem was 
the remediation carried out by the multinational company as it exited Australia in 1987 prior to vacating the site to an "industrial" (as opposed to a "residential") standard. By the 1990s, the site had been vacated and the land had been cleared of built structures. However, the land was known to be contaminated and at the time, not suitable for residential development.

Migration of wastes off site had also occurred, with chlorinated wastes found in adjacent river embayment sediments and in marine organisms in the river. This resulted in a fishing ban being placed over the embayment in 1989 and downriver in 1990. As a result of leaching, sediments are heavily contaminated to a depth of one metre and stretch well out into the embayment.

By the mid 2000s, a decision was made to remediate the land. Part of this process was to process all the soil on the site through a thermal combustion facility. An Environmental Impact Assessment was prepared for the project, and an OHS program was developed for workers at the site, including risk assessments, training, and OHS risk controls. Baseline levels of dioxins in air, as stated in the 2002 Environmental Impact Statement for the project, was 0.1-2.5 $\mathrm{pg} / \mathrm{m}^{3}$ TEQ. This is well within the suggested occupational exposure standard noted earlier, of $15 \mathrm{pg} / \mathrm{m}^{3} \mathrm{TEQ}$, although airborne levels of dioxins while remediation activities were being conducted are likely to be higher than this baseline.

Further, periodic blood dioxin monitoring was required of workers at the site. A benchmark blood dioxin level that was used as an action level for dioxin exposure was $20 \mathrm{pg} / \mathrm{g}$ TEQ blood lipids. This is about double the background level found in a survey of dioxin levels in Australians (10.9 pg/g TEQ blood lipids) carried out by the Commonwealth Government in 2004, and is consistent with baseline data for blood supplied by most workers before working at the site.

Workers from two contracting organisations (A and B) were employed on the site. Blood samples were collected at regular intervals, and shipped to a laboratory certified for dioxin congener analysis in Hamburg, Germany. Dioxins were measured in blood samples using high resolution mass spectrometry and reported as pg/g blood lipids. Some congeners/congener groups were reported as absolute values, others as estimates based on the detection limit (and expressed as ">value". In the analysis of dioxin values used in this report, where such estimates were provided, a fraction of the estimated value was used in total TEQ calculations, of $10 \%$.

Blood dioxin data was expressed in terms of 25 individual dioxin/furan congeners and grouped congeners, including 19 congeners which have toxicity equivalence factors (TEF). This provided individual values for all congeners, and multiplied by the relevant WHO TEF value, allowed calculation of a total TEQ value for each sample. The TEQ of the WHO were used.

\section{Results}

\subsection{Blood dioxin sampling}

Descriptive statistics for the monitoring data provided are shown in Table 1. 
Table 1: Descriptive statistics: monitoring data: samples.

\begin{tabular}{c|c|c}
\hline Parameter & $\begin{array}{c}\text { Company } \\
\text { A Data }\end{array}$ & $\begin{array}{c}\text { Company } \\
\text { B Data }\end{array}$ \\
\hline $\begin{array}{c}\text { Number of Employees/Contractors } \\
\text { Number of Employees/Contractors with No } \\
\text { Samples }\end{array}$ & 71 & 72 \\
\hline Number of Samples & 153 & 7 \\
\hline Number of First Samples & 72 & 62 \\
\hline Number of Second Samples & 46 & 43 \\
\hline Number of Third Samples & 26 & 23 \\
\hline Number of Fourth Samples & 9 & 4 \\
\hline Number of Fifth Samples & 0 & 2 \\
\hline Number of Sixth Samples & 0 & 1 \\
\hline
\end{tabular}

\subsection{Baseline blood dioxin levels}

Analysis of data from the first sample provided by all workers allows an examination of baseline dioxin levels in this group of workers. This analysis is shown in Table 2.

Table 2: $\quad$ Baseline dioxin data.

\begin{tabular}{c|c|c|c|c|c}
\hline & Count & Mean & St Dev & Highest & Lowest \\
\hline $\begin{array}{c}\text { Company A } \\
\text { Data }\end{array}$ & 72 & 6.82 & 4.58 & 23.37 & 0.64 \\
\hline $\begin{array}{c}\text { Company B } \\
\text { Data }\end{array}$ & 62 & 8.14 & 7.07 & 38.93 & 0.64 \\
\hline
\end{tabular}

The "Highest" values in Table 2 are of interest, in that they indicate outlier baseline dioxin levels that may indicate an upper limit of normal vales in this group of workers.

Congener profile data in all samples is shown in Table 3

Table 3: $\quad$ Baseline dioxin data.

\begin{tabular}{c|c|c|c|c|c|c}
\hline Congener & \multicolumn{3}{|c|}{ Company A Data } & \multicolumn{3}{c}{ Company B Data } \\
\hline Group & Mean & \% of Tot & St Dev & Mean & \% of Tot & St Dev \\
\hline Tetra-Cl & 0.9 & $13 \%$ & \pm 1.00 & 1.4 & $18 \%$ & \pm 1.7 \\
\hline Penta-Cl & 4.1 & $60 \%$ & \pm 2.9 & 4.3 & $54 \%$ & \pm 4.1 \\
\hline Hexa-Cl & 1.5 & $22 \%$ & \pm 1.2 & 1.8 & $23 \%$ & \pm 2.3 \\
\hline Septa-Cl & 0.3 & $4 \%$ & \pm 0.4 & 0.4 & $5 \%$ & \pm 0.7 \\
\hline Octa-Cl & 0.03 & $0.4 \%$ & \pm 0.01 & 0.02 & $0.5 \%$ & \pm 0.01 \\
\hline
\end{tabular}


There were six baseline values (two from Company A, four from Company B) that were above the action level of $20 \mathrm{pg} / \mathrm{g}$, shown in Table 4.

Table 4: $\quad$ Baseline dioxin data: outliers above $20 \mathrm{pg} / \mathrm{g}$.

\begin{tabular}{c|c|c|c|c|c|c|c|c|c|c}
\hline \multicolumn{10}{c}{ Dioxin TEF } \\
\hline Total & \multicolumn{1}{|c|}{ Tetra-Cl } & \multicolumn{2}{c|}{ Penta-Cl } & \multicolumn{2}{c}{ Hexa-Cl } & \multicolumn{2}{c}{ Septa-Cl } & \multicolumn{2}{c}{ Octa-Cl } \\
\hline & $\mathrm{pg} / \mathrm{g}$ & $\%$ & $\mathrm{pg} / \mathrm{g}$ & $\%$ & $\mathrm{pg} / \mathrm{g}$ & $\%$ & $\mathrm{pg} / \mathrm{g}$ & $\%$ & $\mathrm{pg} / \mathrm{g}$ & $\%$ \\
\hline 20.3 & 0.2 & 1 & 14.1 & 69 & 4.5 & 22 & 0.6 & 3 & 0.05 & 0.2 \\
\hline 38.9 & 2.3 & 6 & 19.0 & 49 & 15.3 & 39 & 0.9 & 2 & 0.04 & 0.1 \\
\hline 26.2 & 2.3 & 9 & 15.6 & 60 & 6.6 & 25 & 0.6 & 2 & 0.04 & 0.2 \\
\hline 24.7 & 0.4 & 2 & 15.8 & 64 & 6.5 & 26 & 1.0 & 4 & 0.04 & 0.2 \\
\hline 23.4 & 4.0 & 17 & 12.5 & 53 & 6.0 & 26 & 0.8 & 3 & 0.06 & 0.3 \\
\hline 20.4 & 2.5 & 12 & 12.1 & 59 & 4.9 & 24 & 0.4 & 2 & 0.06 & 0.3 \\
\hline
\end{tabular}

\subsection{Blood dioxin results (all samples)}

Data for all blood samples are shown in Figure 1 (Company A data) and Figure 2 (Company B data). For comparison purposes, these are drawn on the same axes.

\subsection{Blood dioxin levels as a function of sample sequence}

There was a steady increase in blood dioxin as the sample sequence increased (as shown chronologically in Figures 1 and 2). The number of samples fell as

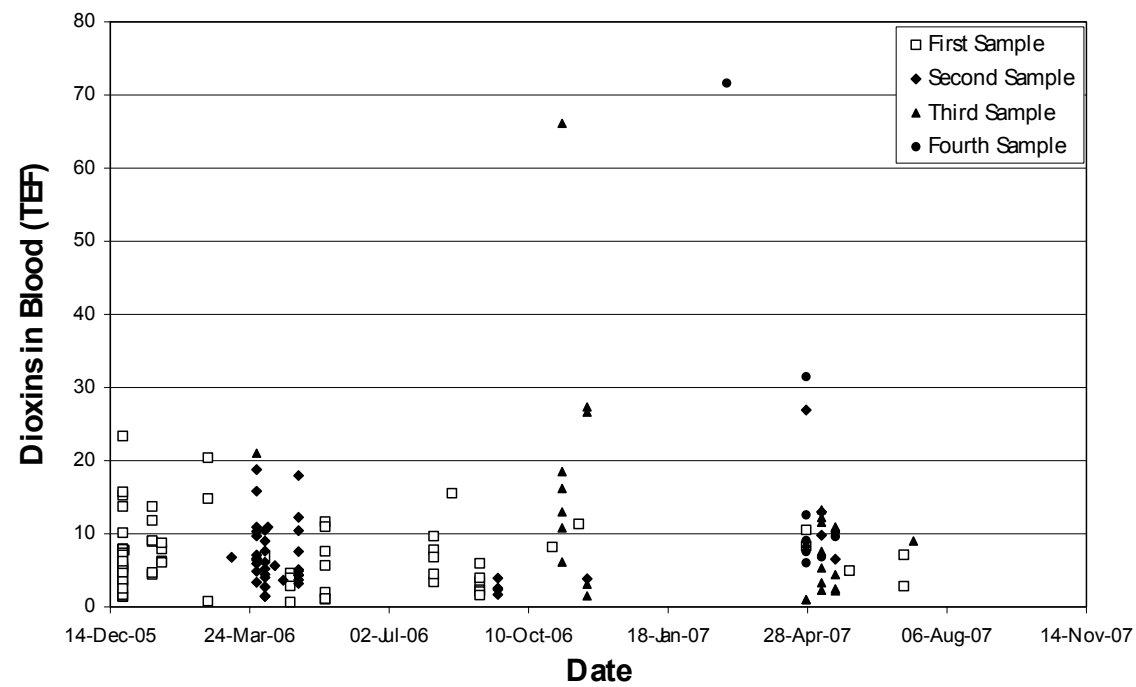

Figure 1: Total dioxin in blood (as TEF), company A data. 


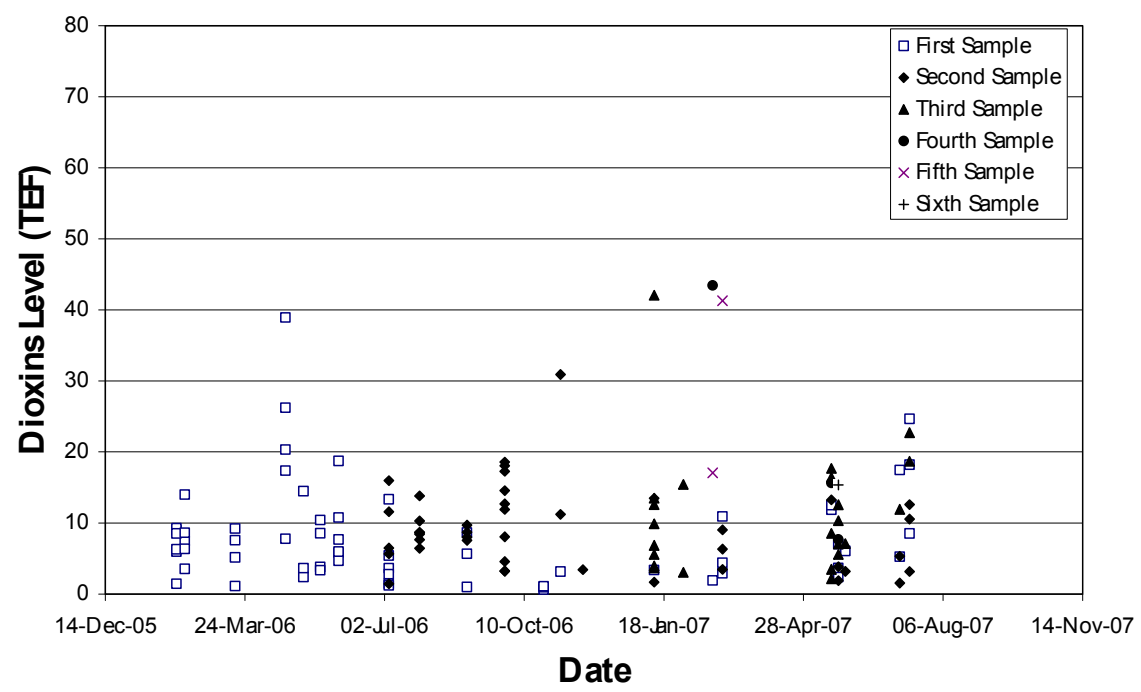

Figure 2: $\quad$ Total dioxin in blood (as TEF), company B data.

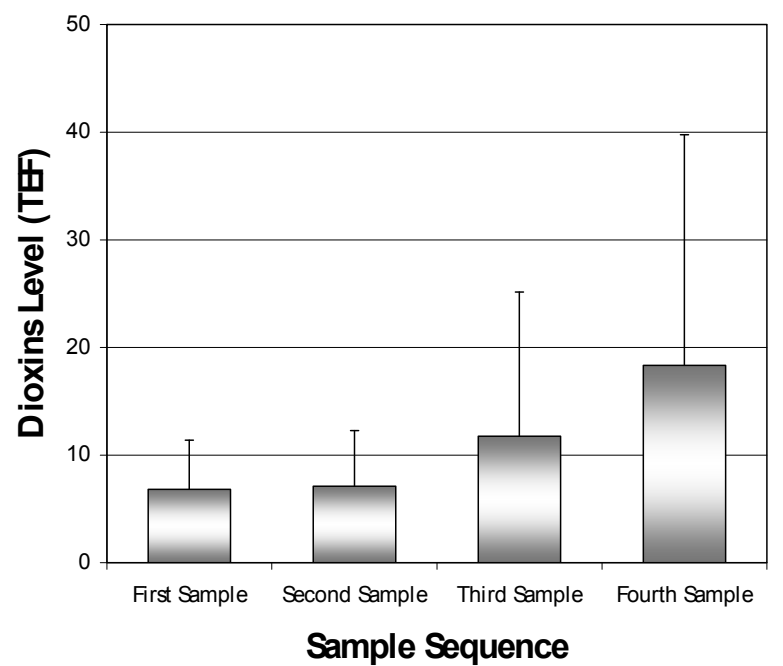

Figure 3: Total dioxin in blood (as TEQ), as sample sequence, company A data.

sampling continued (see Table 1), although these data vary considerably. How blood dioxin levels changed over time through the sampling sequence is shown in Figures 3 and 4.

The congener profile of these values (by sample) is shown in Figures 5 and 6 (again, drawn to the same scale for comparison purposes). 


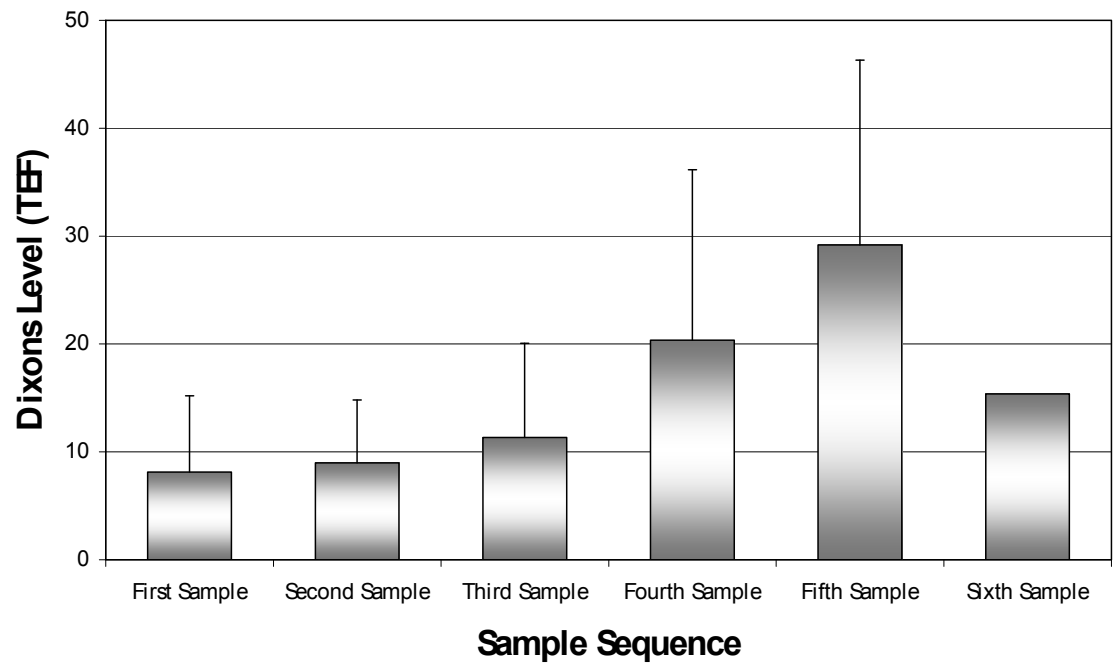

Figure 4: Total dioxin in blood (as TEQ), as sample sequence, company B data.

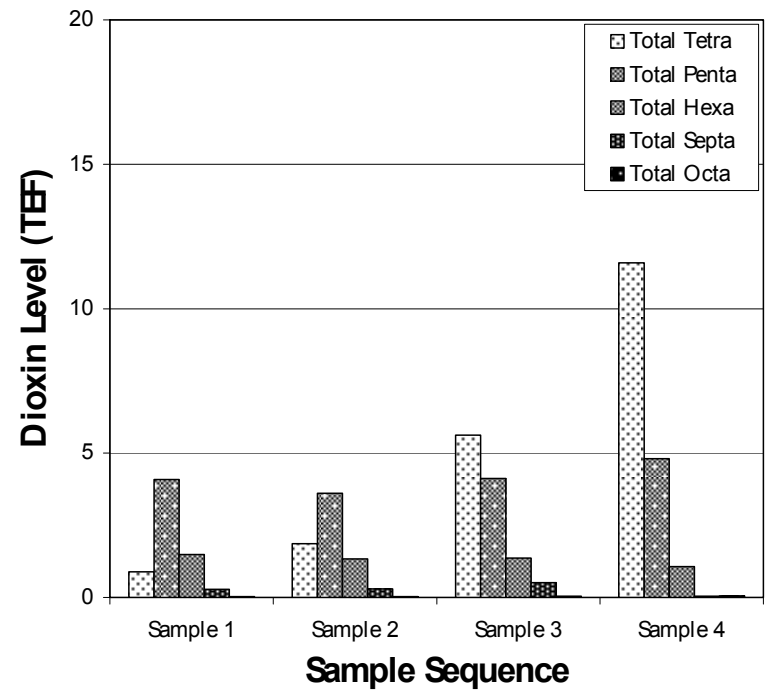

Figure 5: Total dioxin in blood (as TEF), as sample sequence, company A data, congener profile. 


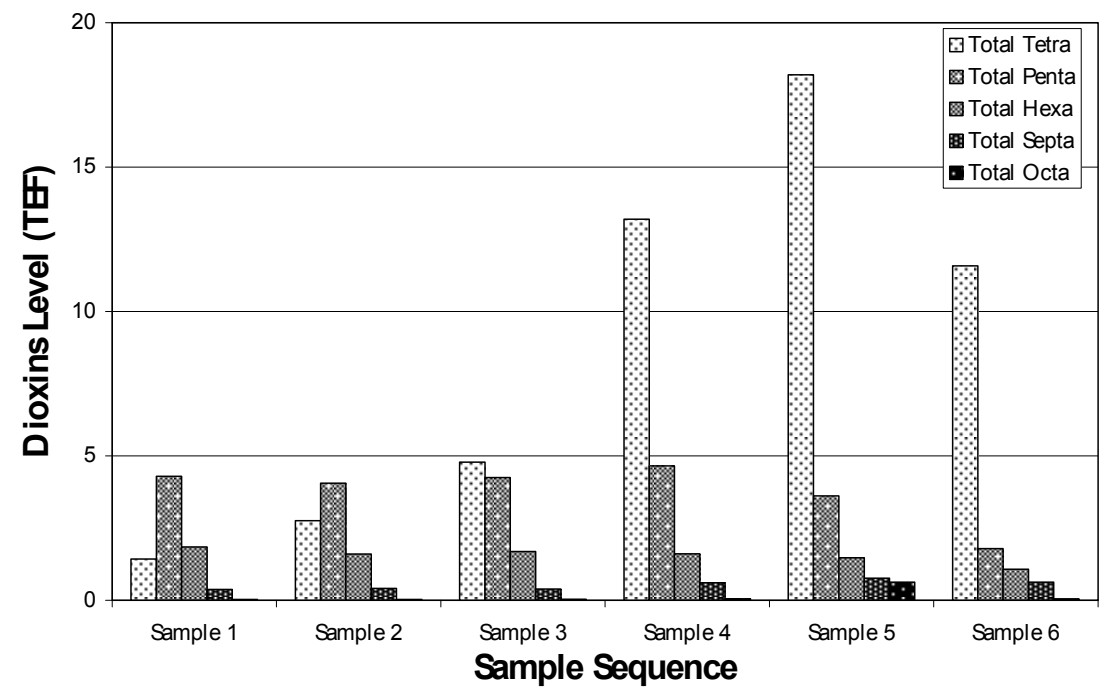

Figure 6: Total dioxin in blood (as TEF), as sample sequence, company B data, congener profile.

\subsection{Data on outliers}

On occasion, blood dioxins levels for a number of workers at the site exceeded $20 \mathrm{pg} / \mathrm{g}$ TEQ in blood lipids. Curves for individual workers are shown in Figures $7 \mathrm{a}$ and $7 \mathrm{~b}$.

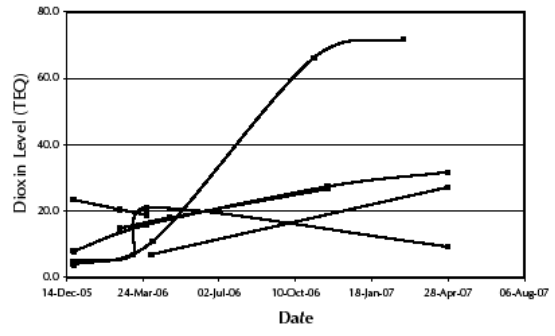

a: Company A Data

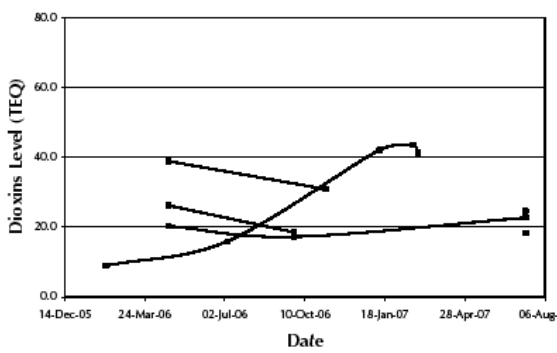

b: Company B Data

Figure 7: Total dioxin in blood (as TEF), outliers.

\section{Discussion}

Human biomonitoring of dose and biological effect nowadays has tremendous utility for providing an efficient and cost effective means of measuring human exposure to chemical substances [15]. While not preventive in approach, this method offers the means to identify and quantify human exposure and risk, to 
gain information about toxicity and exposure, and to assess the adequacy of occupational health controls. In this study, biomonitoring of workers was used to identify trends in exposure to dioxins on a major remediation project of established dioxin contamination in Sydney, Australia. With an overall mean of $7.43 \mathrm{pg} / \mathrm{g}$ in baseline levels (that is, before working on the project; see Table 2) of blood dioxins in workers engaged on this project, it is apparent that these blood dioxin levels, compare favourably with those of the 2004 survey of Dioxins in Australian published the Commonwealth Government (of $10.9 \mathrm{pg} / \mathrm{g}$ ).

The congener profile of these baseline values (see Table 3), shows that the main congeners contributing to baseline values are from the penta- $(60 \%$ and $54 \%$ of total) and hexa- (22\% and $23 \%$ of total) chlorinated dioxins and furans. The level of $20 \mathrm{pg} / \mathrm{g}$ TEF in blood lipids, being approximately double the baseline level for Australians, was suitable for use as an action level in the occupational environment.

Reviewing the congener profile data in six levels above $20 \mathrm{pg} / \mathrm{g}$ blood lipids, it is apparent even with the higher levels, the congener profile is proportionally similar to the other baseline values (see Table 4). For trends in the levels of blood dioxin in all samples (Figures 1-4), the majority of values were below 20 $\mathrm{pg} / \mathrm{g}$. For Company A data this is 144/153 samples (94.1\%) and for Company B data this is $126 / 135$ samples (93.3\%).

Generally, blood dioxin levels increased as time progressed, indicating that working conditions were such that exposure to dioxin contaminated soil was sufficient to increase blood dioxin levels. Overall, blood dioxin levels to Company A workers were higher than Company B workers. It was not possible to identify any specific trends in the activities carried out by workers, as there was considerable flexibility in working arrangements across the site. These data indicate that a number of elevated values occurred during the period October 2006 to April 2007, suggesting that worker or site activities were such that increased exposure to dioxins occurred.

The congener profile data shown in Figures 5 and 6 suggests that while the dioxin/furan concentration (as TEF) of worker blood samples remains largely the same for penta-, hexa-, septa- and octa- congeners, there is a substantial increase in tetra- congeners as the sample sequence progresses. As the most obvious source of this increase is exposure to contaminated soil as part of working at the site, such an increase could be used to identify that component of body burden of dioxins in these samples arises out of industrial exposure. Other studies have suggested that employment history is an important determinant of dioxin levels, and this was identified in the present study [16].

Further, as this congener group contains the most toxic of the congeners (2,3,7,8-tetrachloro-para-dibenzodioxin) this raises issues that may need further attention, especially with regard to on site controls, control of occupational exposure and worker personal hygiene. 


\section{Acknowledgements}

The authors gratefully acknowledge the support and contribution to this project by Thiess Services Pty Ltd.

\section{References}

[1] Gaudet, B. Risk Assessment of Dioxins. VGM Verlag, Saarbrücken, 2009.

[2] Lowe, J.A. Methods of estimating toxic equivalents for polychlorinated dibenzodioxins and dibenzofurans. Chapter 12 (pp 237-248) In: HattemerFrey HA and Travis C, editors. Health Effects of Municipal Waste Incineration. CRC Press, Boca Raton, 1991.

[3] Mukerjee, D., Cleverly, D. Risks from exposure to polychlorinated dibenzo- $p$-dioxins and dibenzofurans emitted from municipal incinerators. Waste Management Research 5: 269-273, 1987.

[4] Van den Berg, M., Birnbaum, L., Bosveld, B.T.C., Brunstrom, B., Cook, P., Feeley, M., Giesy, J.P., Hanberg, A., Hasegawa, R., Kennedy, S.W., Kubiak, T., Larsen, J.C., van Leeuwen, F.X.R., Liem, A.K.D., Nolt, C., Peterson, R.E., Poellinger, L., Safe, S., Schrenk, D., Tillit, D., Tysklind, M., Younes, M., Waern, F, Zacharewski, T. Toxic equivalency factors (TEFs) for PCBs, PCDDs, PCDFS for humans and wildlife. Environmental Health Perspectives 106: 775-782, 1998.

[5] US EPA. Exposure and Health Assessment for 2,3,7.8-Tetrachlorodibenzop-dioxin (TCDD) and Related Compounds. NCEA Office of Research and Development, US Environmental Protection Agency, Washington, 2000.

[6] Gough, M., Turnbull, D. Estimating the Cancer Risks of exposure to 2,3,7,8-tetraclorodibenzo-p-dioxin. Chapter 7 (pp 131-146) In: HattemerFrey, H.A., Travis, C., editors. Health Effects of Municipal Waste Incineration. CRC Press, Boca Raton, 1991.

[7] Hay, A. Identifying carcinogens. Nature 269: 468, 1977.

[8] Poland, A., Palen, D., Glover, E. Tumor promotion by 2,3,7,8Tetrachlorodibenzo-p-dioxin in skin of HRS/J mice. Nature 300: 217-272, 1982.

[9] Pitot, H.C., Goldsworthy, T., Campbell, H.A., Poland, A. Quantitative evaluation of the promotion by 2,3,7,8-tetrachlorodibenzo-p-dioxin of hepatocarcinogenesis from diethylnitrosamine. Cancer Research 40: 3616$3627,1980$.

[10] IARC. IARC Monographs on the Evaluation of Carcinogenic Risk to Humans: Polychlorinated Dibennzo-para-Dioxins and Polychlorinated Dibenzofurans, Volume 69. International Agency for Research on Cancer, Lyon, 1997.

[11] Steenland, K., Bertazzi, P., Baccarelli, A., Kogevinas, M. Dioxin revisited: Developments since the 1997 IARC classification of dioxin as a human carcinogen. Environmental Health Perspectives 112: 1265-1268, 2004. 
[12] Popp, J.A., Crouch, E., McConnell, E.E. A weight of evidence analysis of the cancer dose response characteristics of 2,3,7,8-tetrachlorodibenzodioxin (TCDD). Toxicological Science 89: 361-369, 2006.

[13] NHMRC. Dioxins: Recommendations for a Tolerable Monthly Intake for Australians. National Medical Research Council, Canberra, 2002.

[14] Harden, F., Muller, J., Toms, L. Dioxins in the Australian Population: Technical Report No 9. National Dioxins Program, Department of Environment and Heritage, Canberra, 2004. At: http://www.environment.gov.au/settlements/publications/chemicals/dioxins /report-9/pubs/report-9.pdf

[15] Angerer, J., Ewers, U., Wilhelm, M. Human biomonitoring: State of the art. International Journal of Environmental Health 210: 201-228, 2007.

[16] Burns, C.J., Collins, J.J., Humphry, N., Bodner, K.M., Aylward, L.L., McBride, D. Correlates of serum dioxin to self reported exposure factors. Environmental Research 110: 131-136, 2010. 